\title{
Prevalence of Hepatitis B \& C in Thalassemia Patients in a Tertiary Care Hospital in West Bengal.
}

\author{
Chattopadhyay $\mathrm{S}^{1}$, Mukherjee $\mathrm{R}^{2}$, Nandi $\mathrm{A}^{3}$, Chakraborty $\mathrm{PS}^{4}$, Rit $\mathrm{K}^{5}$, \\ Chaudhuri $\mathrm{SJ}^{6}$. \\ ${ }^{l}$ Demonstrator/RMO, Department of Microbiology, Institute of Post Graduate Medical Education and \\ Research, Kolkata. \\ ${ }^{2}$ M.O.Swasthya Bhavan, Kolkata. \\ ${ }^{3}$ Demonstrator/RMO, Department of Microbiology, Medical College, Kolkata \\ ${ }^{4}$ Demonstrator/RMO, Department of Microbiology, Institute of Post Graduate Medical Education and \\ Research, Kolkata \\ ${ }^{5}$ Assistant Professor, Department of Microbiology, Institute of Post Graduate Medical Education and Research, \\ Kolkata \\ ${ }^{6}$ M.O. Swasthya Bhavan, Kolkata.
}

\begin{abstract}
:
Background: Hepatitis B is a major cause of chronic liver disease. Worldwide approx. 2 billion people are infected, 350 - 400 million people have the active HBV infection and more than 1 million people are dying due to it annually. Hepatitis $C$ has emerged as a major cause of end-stage liver disease. Both the viruses are transfusion - transmitted as well as spread in the laboratory via infected needles.

Aims: Evaluation of seropositivity of Hepatitis $B \& C$ among Thalassemia patients attending the OPD of a Thalassemia Clinic of a Tertiary Care Hospital.

Material \& Methods: A study was conducted on Multitransfused Thalassemia patients for six months from Jan'2011 - June'2011. Test for HB sAg, HBeAg were performed to detect Hepatitis B and anti - HCV antibody to detect Hepatitis $C$ - both by ELISA method.

Results: 379 blood samples were studied -14(3.69\%) HB sAg positive, 4(1.055\%) HBeAg, and 34(8.97\%) positive for anti-HCV. Three (0.79\%) patients showed seropositivity for both $\mathrm{HB}$ sAg and anti HCV. Out of the $14 \mathrm{HB}$ sAg seropositivity cases, $13(3.43 \%)$ were male of which $6(1.58 \%)$ were in the age group $(0-10$ yrs).Out of the 34 anti - HCV positive cases, 25 (6.59\%) were male; of this $13(3.43 \%)$ were in the age group $(0-10$ yrs). Conclusion: More sensitive screening tests and stringent donor selection processes are required for the better control of this transfusion - transmitted infections among Thalassemia patients.
\end{abstract}

Keywords: Hepatitis B \& $C$, end - stage liver disease, Thalassemia, ELISA.

\section{Introduction}

Viral hepatitis is a serious global public health problem. There are six distinct types of hepatitis virus-hepatitis $A, B, C, D, E$ and $G$ viruses. Hepatitis $B$ virus $(H B V)$, Hepatitis $C$ virus $(H C V)$, and Hepatitis $D$ virus (HDV) are blood borne viruses transmitted through a breach in the skin or mucosa in intravenous drug users, through blood transfusions, hemodialysis, needle-stick injuries, tattooing, sexual intercourse and peri-natal infections ${ }^{1}$.

$H B V$ and $H C V$ can also be transmitted sexually. Sexual partners of $H B V$ carriers are at increased risk of infection and should be either vaccinated or should use barrier contraceptives. In $H C V$, the risk of sexual transmission is from $0 \%$ to $0.6 \%$ per year for persons in monogamous relationships. Nonsexual infection of household members (siblings, offspring, and parents) is also possible but has low probability ${ }^{2}$.

In developing countries, use of reused needles and syringes for therapeutic injections and improper sterilization of invasive medical devices is the major vehicle for transmission of blood borne organisms including hepatitis B virus $(H B V), H C V$ and $H I V^{l}$.

$H B V$ and $H C V$ leads to acute hepatitis which clears within 6 months in $80 \%$ cases of $H B V$ and $20 \%$ of $H C V$ cases. In the rest, the virus becomes chronic and may progress to chronic liver disease, including hepatocellular carcinoma and cirrhosis-related end-stage liver disease ${ }^{1}$. WHO estimates that worldwide there are 350-400 million people with chronic $H B V$ infection and 170 million people with chronic $H C V$ infection. Hepatitis $B$ is estimated to result in 5, 63000 deaths and hepatitis $C$ in 3, 66000 deaths annually ${ }^{3}$. These infections lead to a high burden of chronic disease, disability and death. Hence the purpose of this study is to evaluate the seropositivity of Hepatitis $B \& C$ among Thalassemia patients transmitted by blood transfusion. 


\section{Material \& Methods}

A cross - sectional study was carried out in department of Microbiology of a tertiary care hospital on multi-transfused Thalassemia patients for a period of six months from Jan'2011 - June'2011. Informed consent and ethical clearance was taken.A total of 379 blood samples of both sexes and of all age groups were collected. Enzyme linked isosorbent assay (ELISA) to detect HB sAg, HBeAg to identify Hepatitis $B$ and anti $\mathrm{HCV}$ antibody to detect Hepatitis $C$ was done using third generation ELISA kits obtained from NIV Pune.

\section{Results}

379 blood samples were analyzed. Highest prevalence of anti HCV positive samples was detected in the age group 0-10yrs --14 cases (41.17\%).Highest prevalence of $\mathrm{HB}$ sAg positive samples was detected in the age group $0-10 \mathrm{yrs}--7$ cases $(50 \%)$.(Table 1 .)

Table 1: Age Sex Prevalence Of Hbv \& Hcv

\begin{tabular}{|c|c|c|c|c|c|c|c|c|c|}
\hline AGE & $\begin{array}{l}\text { Total } \\
\text { Male }\end{array}$ & $\begin{array}{l}\text { Total } \\
\text { Female }\end{array}$ & $\begin{array}{l}\text { +anti } \\
\text { HCV } \\
\text { Male }\end{array}$ & $\begin{array}{l}+\quad \text { anti } \\
\text { HCV } \\
\text { female }\end{array}$ & $\begin{array}{l}+\mathrm{HB} \\
\text { sAg } \\
\text { Male }\end{array}$ & $\begin{array}{l}+\mathrm{HB} \\
\text { sAg } \\
\text { Female }\end{array}$ & $\begin{array}{ll}\text { +HB e } \\
\text { Ag } \\
\text { Male }\end{array}$ & $\begin{array}{l}\text { +HB } \\
\text { e Ag } \\
\text { Female }\end{array}$ & $\begin{array}{l}\text { Both } \\
\text { anti } \\
\text { HCV } \\
\text { \&HBV }\end{array}$ \\
\hline 0-10yrs & 86 & 31 & 12 & 1 & 6 & 1 & 2 & 1 & 2-male \\
\hline 11-20yrs & 75 & 48 & 8 & 6 & 4 & 0 & 1 & 0 & 1-male \\
\hline 21-30 yrs & 41 & 32 & 4 & 1 & 3 & 0 & 0 & 0 & 0 \\
\hline 31-40yrs & 20 & 21 & 1 & 0 & 0 & 0 & 0 & 0 & 0 \\
\hline 41-50 yrs & 12 & 7 & 0 & 1 & 0 & 0 & 0 & 0 & 0 \\
\hline $51-60$ yrs & 5 & 0 & 0 & 0 & 0 & 0 & 0 & 0 & 0 \\
\hline 61\& above & 1 & 0 & 0 & 0 & 0 & 0 & 0 & 0 & 0 \\
\hline TOTAL & 240 & 139 & 25 & 9 & 13 & 1 & 3 & 1 & 3 \\
\hline
\end{tabular}

\section{Discussion}

Thalassemia patients have inherent defect in the synthesis of hemoglobin and this leads to anemia. The patients require long-term and multiple blood transfusions to decrease the complications of severe anemia and prolong their survival rate. But this recurrent blood transfusion increases the risk of transmission of transfusionrelated viruses--hepatitis $B$ and $C$ viruses and HIV infections ${ }^{4}$. The risk of HIV infection by transfusion is very low. $H B V$ infection to a great extent is prevented by immunization. $H C V$ infection has become an important complication in multiply transfused patients. The increase in seropositivity increases with the number of transfusions and has led to high morbidity in Thalassemia patients. $H C V$ hepatitis is associated with a greater risk of chronic liver disease than $H B V$ hepatitis ${ }^{5}$.The incidence of chronic hepatitis $C$ was very high among Thalassemia patients before 1992, when screening of blood donors was not done but nowadays with mandatory screening of blood products chronic hepatitis $C$ has decreased to some extent ${ }^{2}$.

In the developed countries blood transfusions are safe; however there is a small amount of residual risk limited to blood collected during the "window period," i.e. the period between infection and the time when antibodies against the $H C V$ can be detected in the serum. To minimize even this residual risk, the developed countries have adopted HBV-DNA and HCV-RNA by nucleic acid technology. The risk transmissions is, thus, at present less than 2.5 per 1 million cases in the United States, Canada, and several European countries ${ }^{2}$.

In the developing countries the situation is different. Pre-transfusion HCV antibody screening is not always done. Even the patients/parents are not aware of the importance of HCV antibody screening of transfused blood $^{5}$

\section{Conclusion}

Strict universal safety precautions including vaccination against hepatitis $B$ can reduce the transmission of these blood borne pathogens. The prevalence of hepatitis due to $H C V$ is alarmingly increasing in our population. Health awareness can lead to reduced spread of $\mathrm{HCV}$ infection. Regular screening for these pathogens, early diagnosis during asymptomatic period and proper treatment with anti viral drugs can reduce the morbidity and complications of chronic hepatitis.

\section{Acknowledgement}

I express my heartfelt thanks and gratitude to my institution, Calcutta School of Tropical Medicine for allowing me to conduct the study. 


\section{References}

[1]. Bosan A, Qureshi H, Bile KM, Ahmad I, Hafiz R. A review of hepatitis viral infection in Pakistan. J Pak Med Assoc 2010 Dec; 60(12):1045-58.

[2]. Marco VD, Capra M, Angelucci E, Borgna-Pignatti C, Telfer P. Management of chronic viral hepatitis in patients with Thalassemia: recommendations from an international panel. Blood 2010 Oct 21; 116(16):2875-83.

[3]. 3) Ali S A, Donahue RM.J., Qureshi H, Vermund SH. Hepatitis B and hepatitis C in Pakistan: prevalence and risk factors. International Journal of Infectious Diseases 2009; 13:9-19.

[4]. Mallat ME ${ }^{1}$, Sharara AI . Treatment and prevention of Hepatitis B and C in Thalassemia. Hemoglobin 2009; 33 suppl 1: S $139-44$.

[5]. Younus M, Hassan K, Ikram N, Naseem L, ZaheerHA ,Khan MF. Hepatitis C Virus Seropositivity in Repeatedly Transfused Thalassemia Major Patients. International Journal of Pathology; 2004; 2(1):20-23. 